\title{
Management and Support of Shared Integrated Library Systems
}

The University of Nevada, Las Vegas (UNLV) University Libraries has hosted and managed a shared integrated library system (ILS) since 1989. The system and the number of partner libraries sharing the system has grown significantly over the past two decades. Spurred by the level of involvement and support contributed by the host institution, the authors administered a comprehensive survey to current Innovative Interfaces libraries. Research findings are combined with a description of UNLV's local practices to provide substantial insights into shared funding, support, and management activities associated with shared systems.

$\mathrm{S}$ ince 1989, the University of Nevada, Las Vegas University Libraries has hosted and managed a shared integrated library system (ILS). Currently, partners include the University of Nevada, Las Vegas University Libraries (consisting of one main and three branch libraries, and hereafter referred to as UNLV Libraries); the administratively separate UNLV Law Library; the College of Southern Nevada (a community college system consisting of three branch libraries); Nevada State College; and the Desert Research Institute. The original ILS installation included just the UNLV Libraries and the Clark County Community College (now known as the College of Southern Nevada). The Desert Research Institute joined in the early 1990s, the UNLV Law Library joined with the establishment of the William J. Boyd School of Law in 1998, and, finally, Nevada State College joined upon its creation in 2002. Over time, the technological underpinnings of the ILS have changed tremendously and have migrated firmly into a webbased environment unknown in 1989. The system was migrated to Innovative Interfaces' current java-based platform, Millennium, beginning in 1999. Since the original installation, there have been three major full hardware migrations, in 1997, 2002, and 2009. Over time, regular Innovative software updates, as well as additional purchased software modules, have greatly extended both the staff and end user functionality of the ILS.

In early 2001, UNLV and its partners conducted a marketplace assessment of ILS vendors catering to academic customers. ${ }^{1}$ The assessment reaffirmed the consortia's commitment to Innovative Interfaces. Shortly thereafter,

Jason Vaughan (jason.vaughan@unlv.edu) is Director, Library Technologies, University of Nevada Las Vegas. Kristen Costello (kristen.costello@unlv.edu) is Systems Librarian, University of Nevada Las Vegas. the second major hardware migration occurred, and an initial memorandum of understanding (MOU) was drafted by the UNLV Libraries. This MOU is still used by the libraries. The MOU was discussed with all partners and ultimately signed by the director of each library. Since the MOU was signed nearly a decade ago, the system has continued to grow by all measures-size of the database, number of users, number of software modules comprising the complete system, and the financial and staff commitment toward support and maintenance. Despite the emergence of a large number of other network-based technologies critical to library operations and services, the ILS remains a critical system that supports many library operations. The research described in this paper developed in part because there is a dearth of published survey-based research of shared ILS management and financial support. This article interweaves local existing practices with research findings. For brevity's sake, the system shared by the UNLV University Libraries and four additional partners will be referred to as UNLV's system. To provide a relative sense of the footprint of each partner on the system, various measures can be used (see figure 1).

\section{Survey Method}

In April 2010, the authors administered a 20-question survey to the Innovative User's Group (IUG) via the group's listserv. The survey focused on libraries that are part of a consortial or otherwise shared Innovative ILS. The Innovative User's Group is the primary user's group associated with the Innovative ILS and suite of products. The IUG hosts a busy listserv, coordinates the annual North American conference devoted solely to the Innovative system, and provides Innovative customer-driven enhancement requests. To prevent multiple individuals from the same consortium responding to the survey, instructions indicated that only one individual from the main institution hosting the system should officially respond. Given the anonymity of the survey and the desire to provide confidentiality, there is the possibility that some survey responses refer to the same system. The survey consisted primarily of multiple choice, "select all that apply," and free-text response questions. The survey was divided into four broad topical areas: (1) background information; (2) funding; (3) support; and (4) training, professional development, and planning. The survey was open for a period of three weeks. Because respondents could choose to skip questions, the number of responses received per question varied. On average, 43 individual responses were received for each question. Innovative currently has more than 1,200 Millennium ILS installations. $^{2}$ Not all of those installations support multiple, administratively separate library entities. It is unknown 


\begin{tabular}{lrrrrrr}
\hline & $\begin{array}{c}\text { Full-Time } \\
\text { Library Staff }\end{array}$ & $\begin{array}{c}\text { Bibliographic } \\
\text { Records }\end{array}$ & Item Records & $\begin{array}{r}\text { Order } \\
\text { Records }\end{array}$ & $\begin{array}{r}\text { Patron } \\
\text { Records }\end{array}$ & $\begin{array}{c}\text { Staff Login } \\
\text { Licenses }\end{array}$ \\
\hline UNLV Libraries & 105 & $1,494,890$ & $1,906,225$ & 74,223 & 40,788 & 85 \\
& $(70.9 \%)$ & $(78.2 \%)$ & $(81.1 \%)$ & $(58.4 \%)$ & $(59.6 \%)$ & $(69.1 \%)$ \\
UNLV Law & 13 & 246,678 & 243,788 & 29,921 & 2,034 & 13 \\
Library & $(8.8 \%)$ & $(12.9 \%)$ & $(10.4 \%)$ & $(23.5 \%)$ & $(3 \%)$ & $(10.6 \%)$ \\
College of & 27 & 146,118 & 175,862 & 22,142 & 23,876 & 20 \\
Southern & $(18.2 \%)$ & $(7.6 \%)$ & $(7.5 \%)$ & $(17.4 \%)$ & $(34.9 \%)$ & $(16.3 \%)$ \\
Nevada & & & & & & \\
Nevada State & 1 & 17,787 & 17,979 & 841 & 1,718 & $(2.4 \%)$ \\
College & $(.7 \%)$ & $(.9 \%)$ & $(.8 \%)$ & $(.7 \%)$ & $(2.5 \%)$ & $(2.4 \%)$ \\
Desert Research & 2 & 5,396 & 5,361 & 0 & 24 & 2 \\
Institute & $(1.4 \%)$ & $(.3 \%)$ & $(.2 \%)$ & $(0 \%)$ & $(<.1 \%)$ & $(1.6 \%)$ \\
\hline
\end{tabular}

Figure 1. Various Measures of ILS Footprints for UNLV's Shared ILS (percentage of overall system)

Note: "Staff login licenses" refers to the number of simultaneous staff users each institution can have on the system at any given time.

how many shared Innovative library systems exist. While a true response rate cannot be determined, such a measure is not critical for this research. The survey questions with summarized results are provided in appendix A.

\section{Survey Background}

UNLV's system, with only five unique library entities, is a "small" system when compared with survey responses. Survey respondents indicated a range from 2 to 80 unique members sharing their system. Of the 48 responses received for this background question, 26 (54 percent) indicated 10 or fewer partners on the system. Seven (14.6 percent) indicated 40 or more partners. The average number of partners sharing an ILS implementation was 18 and the median was 8.5. There can be varying levels of partnership within a shared ILS system. UNLV's instance is a rather informal partnership. Some survey respondents indicated the existence of a far more structured or dedicated support group not directly associated with any particular library. One respondent noted they have a central office comprised of an executive director and two additional staff, responsible for ILS administration; this central office reports to a board of directors, comprised of library directors for each member library. Another indicated they have a central office responsible not only for the ILS, but for other things such as wide and local area networks and workstation support. One respondent indicated that they are actually a consortium of consortia, with 9 hosts each comprised of anywhere from 4 to 11 libraries.

Twenty-three respondents out of 52 (44.2 percent) indicated that they and all of their current existing partners originally purchased the system together; 20 (38.5 percent) indicated they purchased the system with some of their current existing partners, while 9 (17.3 percent) indicated they as the main institution originally and solely purchased the system. Several of the entities sharing the UNLV Libraries' system did not even exist when the ILS was originally purchased; only two of the current partners shared the original purchase cost of the system.

Another background question sought to understand how partners potentially individualize the system despite being on a shared platform. Innovative, and likely other similar ILS vendors, offers several products to help libraries better manage and control their holdings and acquisitions. Of potential benefit to staff operations and workflow, Innovative offers the option to have multiple acquisitions and/or serials control units, which provide separate fund files and ranges of order records for different institutions sharing the ILS system. Of 51 responses received, 44 respondents (86.3 percent) indicated they had multiple acquisitions and serials units and 7 (13.7 percent) do not. Innovative offers two web-based discovery interfaces for patrons: the traditional online public access catalog, known as WebPAC, and their version of a next-generation discovery layer, known as Encore. Of potential benefit to staff as well as patrons, Innovative offers "scoping" modules that help patrons using one of the web-based discovery interfaces, as well as staff using the Millennium staff modules. The scoping module allows holdings segmentation by location or material type. Scopes allow libraries to define their collections and offer their patrons the option to search just the collection of their applicable library.

Forty-six (88.5 percent) of the 52 respondents indicated they use scoping and 6 (11.5 percent) do not. UNLV 
has multiple serials and acquisitions units as well as multiple scopes configured to help segment the records for each entities' particular collection.

Innovative offers various levels of maintenance support. UNLV's level of support includes the vendor supplying services such as application troubleshooting resolution, software updates, and some degree of operating system and hardware configuration and advice. UNLV also contracts with the hardware vendor for hardware maintenance and underlying operating system support. The UNLV Libraries have had the opportunity to hire fully qualified and capable technical staff to provide a high level of support for the ILS. UNLV's level of vendor support has evolved from an original full turnkey installation with Innovative providing all support to a present level of more modest support. Nearly half of all survey respondents, 25 of 52 (48.1 percent) indicated they had a turnkey arrangement with Innovative; the remaining 27 respondents had a lesser level of support. Maintenance and support obviously carry a cost with one or more third party providers. The majority of the respondents, 40 of 51 (78.4 percent), indicated there is a cost-sharing structure in place where maintenance support costs related to the ILS are spread across partner libraries. Six respondents (11.8 percent) indicated the main institution fully funds the maintenance support costs.

The UNLV Libraries drafted the first and current MOU in 2002 for all five entities sharing the ILS system. Thirty-five of 51 survey respondents (68.6 percent) indicated they, too, have a MOU in place. UNLV's MOU is a basic document, two pages in length, split into the following sections: background; acquisition of new or additional hardware; acquisition of new or additional software; annual maintenance associated with the primary vendor and third party suppliers and, importantly, the associated cost allocation method for how annual support costs are split between the partners; how new products are purchased from the vendor; and management and support responsibilities of the hosting institution. Many of the survey respondents provided details on items contained in their own MOUs, which can be clustered into several broad categories. These include budgeting, payments, funding formulas; general governance and voting matters; support (e.g., contractual service responsibilities, responsibilities of member libraries); equipment (e.g., title and use of equipment, who maintains equipment); and miscellaneous. This latter category includes items such as expectations for record quality; network requirements/ restrictions; fine collection; and holds management.

The majority of UNLV's MOU addresses shared costs for annual maintenance. UNLV's cost-sharing structure is simple. The system has a particular number of associated staff (simultaneous login) licenses, which have gradually increased as the libraries have grown. Logins are separated by institution, and each member is assessed their share of funding toward annual maintenance based on their number of staff licenses, as shown in figure 1.

\section{Funding Support from Partners}

MOUs appear to include funding and budgeting information more than any other discrete topic. Direct support costs can include the maintenance support costs paid to one or more vendors, costs for additional vendor authored software modules purchased in addition to the base software, and, perhaps, licensing costs associated with a database or operating system used by the ILS (e.g., an Oracle license for Oracle based ILS systems). There are many parameters by which costs could be determined for partners, and, given the dearth of published research on the topic, a chief focus of this research sought more information on what factors were used by other consortia. The authors brainstormed 10 elements that could potentially figure into the overall cost sharing method. Thirty-eight respondents provided information on factors playing a role in their cost sharing arrangements, illustrated in figure 2. Respondents could mark more than one answer for this question, as more than one factor could be involved.

The top two factors relate directly to vendor costswhether annual support costs or acquisition of new vendor software. Hardware placed third in overall frequency; for Innovative and likely for other ILS systems, ILS hardware can be purchased from the vendor or an approved platform can be sourced from a reseller directly. Support costs from third parties and the number of staff login ports were each identified as a factor by more than a third of all respondents.

\section{Software Purchases}

Depending on the software, additional modules extending the system capabilities can benefit a single partner, or, in UNLV's experience, all partners on the system. Traditionally, the UNLV Libraries have had the largest operating budget of the group, and a majority of new software requests have come internally from UNLV Libraries staff. Over the past 20 years, the UNLV Libraries have fully funded the initial purchase costs of a majority of the software extending the system, regardless of whether it benefits just the UNLV Libraries or all system partners. There are numerous exceptions where the partner libraries have contributed funding, including significant start-up costs associated with the UNLV Law Library joining the system in 1998 and the addition of Nevada State College in 2002. In both instances, those bodies funded required and recommended software directly applicable 


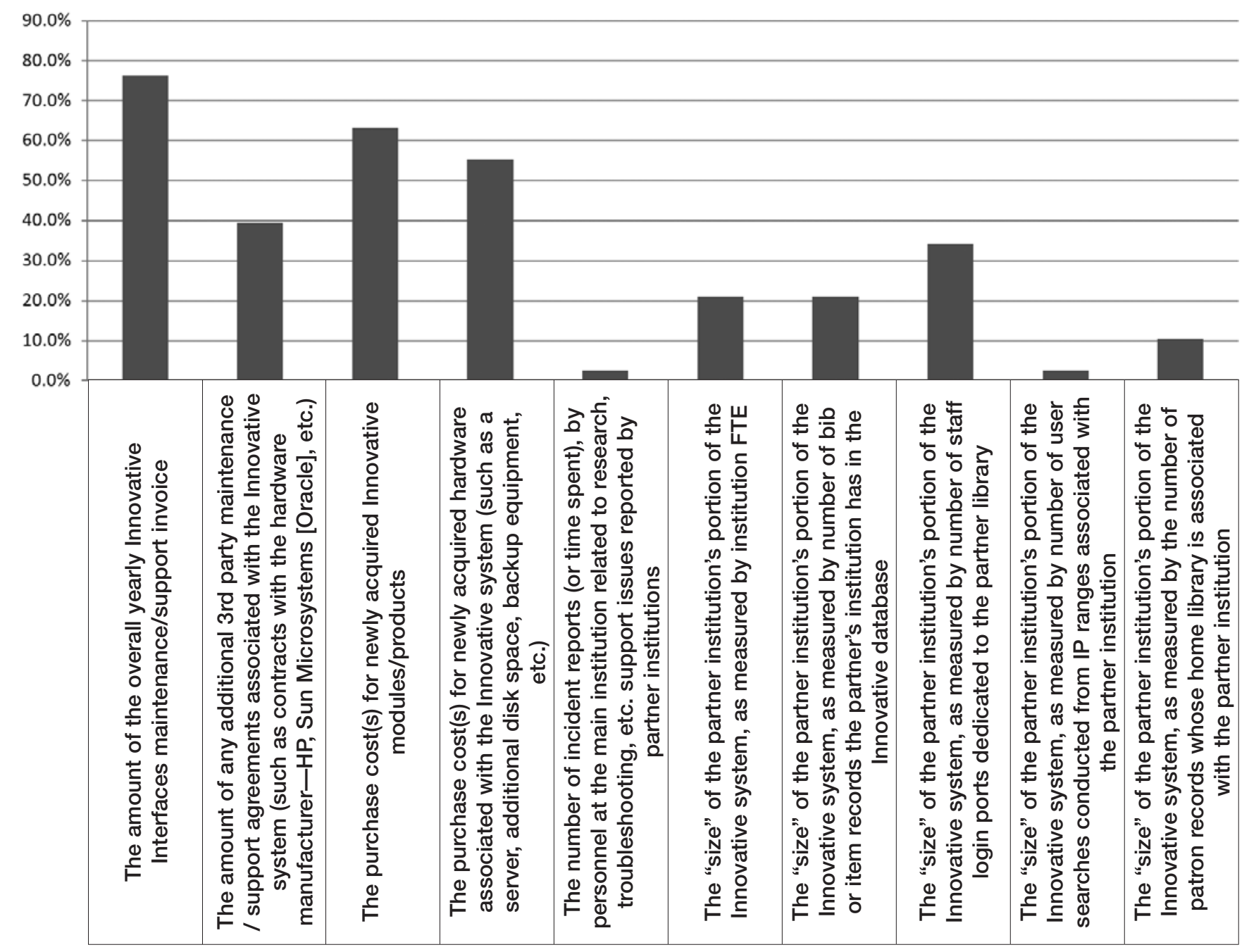

Figure 2. Cost-Sharing Formula Factors

to their operation such as additional serials and accounting units (for the Law Library), check-in and order records, and staff licenses. In addition, when the system was migrated from the aging text-based system (Innopac) to the current Millennium java-based GUI system in 1999, the current partners contributed toward the upgrade cost based on number of staff licenses. Partner institutions have continued to fund items of sole benefit to their operation, such as adding staff licenses or required network port interfaces associated with patron self-check stations installed at their facilities. During the 2000s, the UNLV Libraries have fully funded a majority of software of potential benefit to all partners, such as the electronic resource management module, the Encore next generation discovery platform, and various OPAC/Encore enhancements. Software additions typically increase the annual maintenance bill and all partners help maintain new software acquisitions by contributing toward the annual maintenance.

Regarding new software acquisitions, cost-sharing practices varied between 44 respondents providing information in the survey. Eight (18.2 percent) indicated there is consultation with other partners and there is some arrangement to share costs between the majority or all partners sharing the system. Two respondents (4.5 percent) indicated the institution expressing the initial interest in the product fully funds the purchase. Nineteen respondents (43.2 percent) indicated that they have had instances of both these scenarios (shared funding and sole funding). Two respondents (4.5 percent) indicated they could not recall ever adding any additional software. Thirteen respondents (29.5 percent) offered details 
on other scenarios. Several indicated that if a product is directly applicable to only one library, such as self-check interfaces and additional acquisition units, then the library in need fully funds the purchase, which mirrors the local practice at UNLV. Several respondents indicated that if a product benefits all libraries, then costs are shared equally. One respondent indicated that the partner libraries discuss the potential item, and collectively they may choose not to purchase, even if one or more partners are very interested. In such cases, those partners have the option to purchase the product and must agree to make it available to all partners. Several respondents indicated that, as the largest entity using the shared system, they generally always purchased new software for their operation as needed, with the associated benefit that the other partners of the system were allowed to use the software as well. Three respondents reiterated that a central office funds add-on modules, in one case from funding set aside each year for system improvements. A fourth respondent indicated that a "joiners fee" fund, built up from new members joining the system, allows for the purchase of new software. Clearly there are many scenarios of how new software is funded. Generally, regardless of funding source, sole or share, if a product can benefit all partners, it's allowed to do so.

Thirty-six survey respondents provided details on what factors determine how much each partner contributes toward new software purchases. Seven respondents (19.4 percent) indicated the number of staff licenses plays a role (as in the UNLV model). Three respondents (8.3 percent) indicated that institution FTE played a role, while three other respondents indicated that the number of partner bibliographic/item records played a role. The majority of respondents, 25 (69.4 percent) provided alternate scenarios or otherwise more information. Nine of these 25 respondents indicated costs were split evenly across all partners. Several indicated that the formula used for determining maintenance costs was also applied to new software purchases. Four respondents indicated that the library service population was a factor. Two indicated that circulation counts were a factor. One indicated that it's negotiated on a per purchase basis, based on varying factors.

\section{Hardware Purchases}

Hardware needs related to the underlying infrastructure, such as server(s), disk space, and backup equipment increases as the ILS grows. UNLV's ILS installation has grown tremendously. New software modules have been purchased, application architecture changes occurred with the release of the Millennium suite in the late 1990s, regular annual updates to the system software have been applied, the number of staff users has increased significantly, and the system was migrated to an underlying Oracle database in 2004. Since the original system was purchased in 1989 and fully installed in 1990, the central, locally hosted server has been replaced three times, in 1997, 2002, and 2009. Partners contributed toward the costs of the server upgrades in 1997 and 2002, while the UNLV Libraries fully funded the 2009 upgrade. Software and hardware components comprising the backup system have been significantly enhanced with a modern system capable of the speed, capacity, and features needed to perform appropriately in the short backup window available each night. UNLV funded the initial backup software and hardware, and the partner institutions contribute toward the annual maintenance associated with the backup equipment and software.

One survey question focused on major central infrastructure supporting the ILS (defined as items exceeding $\$ 1,000$ and with several examples listed). The question did not focus on hardware that could be provided by ILS vendors benefiting a single partner, such as self-check stations or inventory devices. Fourteen (31.8 percent) of the 44 respondents indicated that if major new hardware was needed, there was consultation with other partners, and, if purchased, a cost-sharing agreement was arranged. Two respondents ( 4.5 percent) indicated the institution expressing the initial interest fully funds the purchase and seven respondents indicated they've had instances in the past of both these scenarios. Three respondents (6.8 percent) indicated their shared system hardware had never been replaced or upgraded to their knowledge. Nineteen respondents provided information on alternate scenarios or otherwise more details as to local practice. Several indicated a separate fund is maintained solely for large ILS system-related improvements or ILS related purchases. Revenue for these funds can be built up over time through maintenance and use payments by partner libraries or by a small additional fee earmarked for future hardware replacement needs collected each year. One respondent indicated they have been able to get grant funds to cover major purchases. With few exceptions, the majority of free text responses indicated that costs for major purchases were shared by partners or otherwise funded by the central consortium or cooperative agency.

As with regular annual maintenance and new software purchases, various elements can determine what portion of hardware replacement costs are borne by partner libraries. This includes number of staff licenses (21.9 percent of responses), institutional FTE count (15.6 percent), number of bibliographic or item records (15.6 percent), and number of patron records (9.4 percent). Twenty respondents provided additional information. Several indicated that the costs are split evenly across all partners. Several indicated that population served was a factor. Others reiterated that costs for central hardware 
replacements are determined by the same formula used for assessing the share of annual maintenance.

\section{Additional Purchases}

The last funding-related survey question asked if ongoing content enrichment services were subscribed to, and if so, to describe how the cost share amount is determined for partner libraries. Content enrichment services can provide additional evaluative content such as book cover images, table of contents (TOC), and book reviews. UNLV subscribes to a TOC service as well as an additional service providing book covers, reviews, and excerpts. Partner institutions contribute to the annual service charge associated with the TOC service and pay for each record enhanced at their library. UNLV fully funds the book cover/review/excerpt service that benefits all partners. Fourteen of the 43 survey respondents (32.6 percent) indicated they did not subscribe to enrichment services. Twelve respondents (27.9 percent) indicated they had one or more enrichment services and that the costs were fully funded by the main institution. Seventeen respondents (39.5 percent) subscribe to enrichment services and that the costs are shared. Several indicated the existing cost-sharing formula used for other assessments (annual maintenance, hardware, or nonsubscription-based software) is also used for the ongoing enrichment services. One respondent indicated they maintain a collective fund for enrichment services and estimate the cost of all shared subscriptions; this figure is integrated into the share each institution contributes to the central fund annually. One respondent indicated that their system only uses free enrichment services.

\section{Support}

The next section of the survey addressed staff support efforts related to management of the ILS. Twenty years ago when UNLV installed its ILS, staff support included one librarian and one additional staff; both focused on various aspects of system support, from maintaining hardware to working with the vendor, in addition to having other primary job responsibilities completely unrelated to the ILS. In addition, over time, functional experts developed for particular modules of the system, such as cataloging, acquisitions, circulation, and serials control. This group of functional experts eventually became known as the UNLV Innovative Module Coordinators Group, which was chaired by the head of the Library Systems Department. This group met quarterly and included experts from UNLV as well as one representative from each partner institution. Each Module Coordinator served as the contact person charged with maintaining familiarity with the functions and features of a particular module, testing enhancements within new releases, keeping other staff informed of changes, and alerting the system vendor of any problems with the module. Annually, Module Coordinators were to consider new software and prioritize and recommend ILS software the library should consider purchasing. Module Coordinators were tasked to maintain a system-wide view of the ILS and alert others if they discovered problems or made changes to the ILS that could affect other areas of the system. In addition, Module Coordinators were encouraged to subscribe to the IUG listserv to monitor discussions and to maintain awareness of overall system issues. All staff had access to the system's user manual but if they had questions on system features or functions, the Module Coordinator served as an additional resource. In addition, any bug reports were provided to the most appropriate Module Coordinator, who would contact Innovative. The UNLV Systems staff, which has grown over time and is now part of the Library Technologies Division, was responsible for all hardware and networking problems, and for scheduling and verifying nightly data backups. The Systems Department coordinated any new software installations with the Module Coordinators Group, library staff, and library partners.

In 2006, the UNLV Libraries reorganized and hired a dedicated Systems Librarian focused on the ILS. The Systems Librarian's principal job responsibility is to serve as the central administrator and site coordinator of the UNLV Libraries' shared ILS. Responsibilities include communicating with colleagues regarding current system capabilities, monitoring vendor software developments, monitoring how other libraries utilize their Innovative systems, and recommending enhancements. The Systems Librarian is the site contact with Innovative and coordinates and monitors support calls, software and patch upgrades, and new software module installations. The position serves as the contact person for the shared institutions whenever they have questions or issues with the ILS. The Systems Librarian has taken over much of the work previously coordinated through the Module Coordinators Group. While the formal Module Coordinators group no longer exists, module experts still provide assistance as needed, and consultation always occurs with partners on system-wide issues as they arise.

UNLV is not unique in how it manages their ILS. In the survey results, 36 respondents ( 87.8 percent) indicated there is a dedicated individual at the main institution who has a primary responsibility of overseeing the ILS. To help clarify the responses, "primary responsibility" is defined as individuals spending more than half their time devoted to support, research, troubleshooting, and system administration duties related to the ILS. The authors 


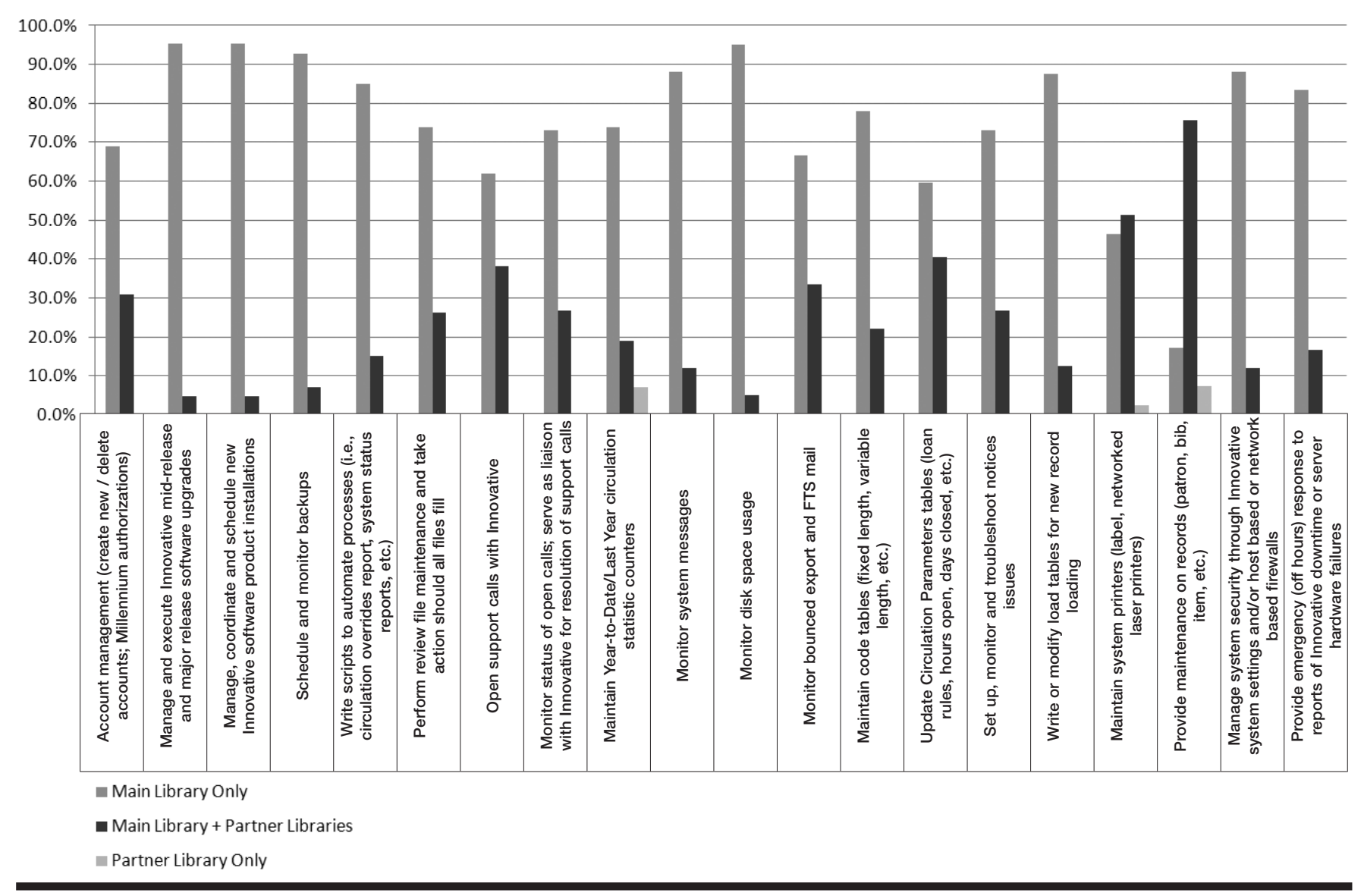

Figure 3. Systems Administration / Support Responsibilities

created a list of 20 duties related to ILS system administration and asked respondents to indicate whether: the main library or a central consortial or cooperative office dedicated to the ILS handles this particular duty; the duty is shared between the main library and partner libraries; or the duty is handled by just a partner library. As illustrated in figure 3 , the survey results overwhelmingly show that the main library in a shared system provides the majority of system administration support. Only two tasks were broadly shared between the main library and partner libraries; maintenance of the institution's records (bibliographic, item, patron, order, etc.) and maintaining network and label printers. Other shared tasks included changes to the circulation parameters tables (e.g., configuring loan rules and specifying open hours and days closed tables for materials they themselves circulate) with 40.5 percent of the respondents indicating this as a shared responsibility, opening support calls with the vendor (38.1 percent), monitoring bounced export and FTS mail (33.3 percent), and account management (31 percent). The more typical system administration activities are done solely by the main library. Typical system administration activities include managing and executing mid-release and major release software upgrades (95.2 percent of all respondents indicated the main library is solely responsible); managing, coordinating, and scheduling new products for installation (95.2 percent); monitoring disk space (95 percent); and scheduling and monitoring backups (92.9 percent). UNLV's ILS support model is very similar to the survey results. The Systems Librarian at UNLV manages all software upgrades, as well as coordinating and scheduling new ILS software product and module installs. The Library Technologies Division monitors and schedules the nightly backups and diskspace usage. Certain UNLV Libraries staff and selected individuals from the partner libraries are authorized to open support calls with the system vendor, although the Systems Librarian often handles this activity herself. Other functions, such as maintaining the year-to-date and last year circulation statistics are also performed by the UNLV Libraries Systems Librarian. Updating circulation parameters are tasks best performed by each of the 


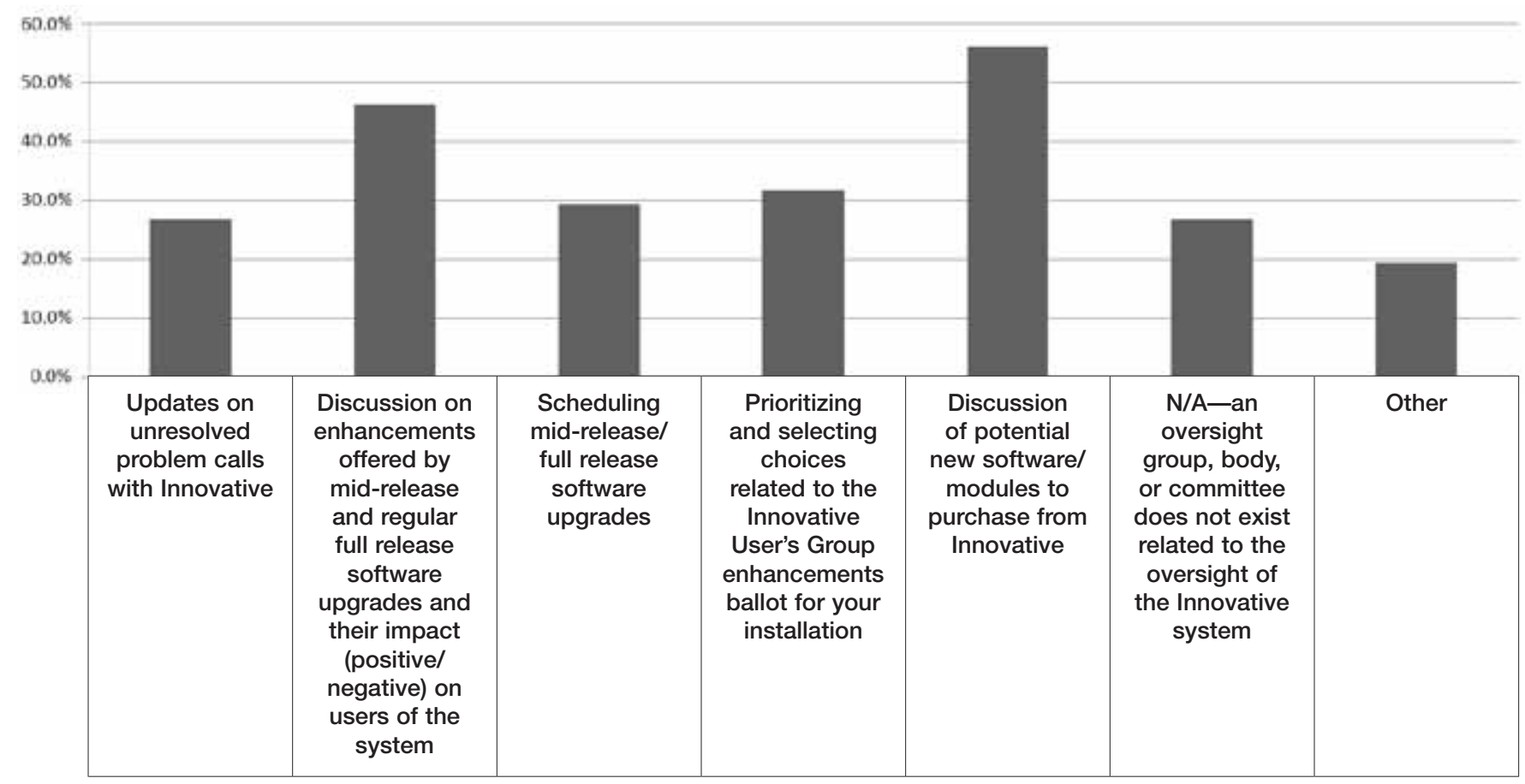

Figure 4. Issues Discussed By ILS Oversight Body

partner institutions, with advice and assistance as necessary provided by the Systems Librarian.

The authors were interested if an ILS oversight body exists with other shared systems, and, if so, what issues are discussed. Responses indicated that a variety of groups exist, and, in some instances, multiple groups may exist within one consortia (some groups have a more specific ILS focus and others a more tangential involvement). As illustrated in figure 4, a minority of respondents, 11 of 41 (26.8 percent), indicated that they do not have a group providing ILS oversight. If such a group exists, respondents were allowed to select various predefined duties performed by that group. Twenty-three respondents indicated the group discusses purchasing decisions. Respondents also indicated that such a group also discusses the impact of the vendor enhancements offered by mid-release and regular full-releases (19), and when to schedule the upgrades (12). The absence of an oversight group doesn't imply that consultation doesn't occur, rather, it may be the responsibility of an individual as opposed to an effort coordinated by a group. Some libraries also have module-driven committees, which disseminate information, introduce new ideas, and try to promote cohesiveness throughout the consortium. Other duties that such an oversight group may focus on include workflow issues, discussion of system issues, and definition of policies and procedures. Some groups provide recommendations to a larger executive board for the consortia. The meeting frequency of these groups is as varied as the libraries. Some groups meet quarterly (33.3 percent) or monthly (20 percent) but the majority meet at other frequencies (40 percent), such as every other month or twice a year. Some libraries use e-mail to communicate as opposed to having regular in-person meetings. In addition to a standing committee focused on the ILS, and similar to UNLV's experience, libraries may have finite working groups to implement particular products.

\section{Training, Professional Development, and Planning}

The survey also focused on training, professional development, and planning activities related to the ILS. There are many methods that library staff can use to stay current with their ILS. Most training methods typically include in-person workshops or online tutorials, as well as other venues for professional development, such as conference attendance. The authors were interested in how libraries sharing an ILS determined training needs and who was responsible for the training. The survey results showed that libraries value a variety of training opportunities, 
regardless of the library's status. The easiest and cheapest method of awareness involves having someone monitor the IUG electronic discussion list, with 29 respondents (70.7 percent) indicating that both the main library and one or more partner libraries participate in this activity. Attendance at the national and regional IUG meetings was also valued highly by libraries with 26 respondents (66.7 percent) indicating both the main libraries and their partner libraries having a staff member attend such meetings in the past 5 years. Sixteen respondents (64 percent) indicated both the main library and their partner libraries regularly send staff to the American Library Association Annual Conference and Midwinter Meeting. IUG typically has a meeting the Friday before the Midwinter Meeting. Attendance at training workshops held at the vendor headquarters, as well as online training, is an activity in which the main library participates more frequently than the partner libraries (61.1 percent). Complete survey results are provided in appendix A, available at http://www.lita.org/ala/mgrps/divs/lita/ ital/302011/3002jun/pdf/vaughan_app.pdf.

\section{Research Summary and Future Directions}

Integrated library systems shared by multiple partners hold the promise of shared efficiencies. Given a rather significant number of responses, shared systems appear to be quite common, ranging from a few partners to systems with many partners. Perhaps reflecting this, shared systems range from loose federations of library partners to shared systems managed by a more formalized, official consortium. A majority of libraries with shared systems have a MOU or other official documents to help define the nature of the relationship, focusing on such topics as budgeting, payments, and funding formulas; general governance and voting matters; support; and equipment. Most libraries sharing a system have a method or funding formula outlining how the ILS is funded on an annual basis and the contributions provided by each partner. Such methods can include not only annual maintenance, but also the procurement of new hardware and software extending the system capabilities. While many support functions are carried out by a central office or staff at the main library hosting the shared system, partner libraries often participate in annual user group and library association conferences where they help stay abreast of vendor ILS developments.

The research above describes the authors' investigations into management of shared integrated library systems. In particular, the authors were interested in how other consortia sharing an ILS managed their system, specifically regarding cost sharing, support, and rights and responsibilities. In conducting this background research, a paucity of published literature was observed, and thus the authors hope the findings above may help other established consortia, who may be interested in reviewing or tweaking their current MOUs or more formalized agreements likely in place. It may also provide some considerations for libraries considering initiating a shared ILS instance, something that, given the current recession, may be a topic to consider. Given that nearly a decade has passed since the original UNLV MOU was drafted and agreed to, several revisions will be proposed and drafted. This includes formalization of how costs are divided for enrichment services (new since the original MOU), and formalization in writing of the coordination role of the Systems Librarian in her capacity as chief manager of the ILS. Other ideas gathered from survey responses are worth consideration, such as a base additional fee contributed each year (above and beyond the fee accessed as determined by staff licenses). Such a fee could help recoup real, sometimes significant costs associated with the system, such as the purchase of additional software benefitting all players (often, in practice funded solely by the main library). Such a fee could also help recoup more tangential (but still real) expenses, such as replacement of backup media. However, at the time of writing, tweaking (increasing) the fee assessed to partner institutions is a delicate issue. As with many other institutions of learning and their associated libraries, the Nevada System of Higher Education has been particularly hard hit with funding cuts, even when compared against serious cuts experienced by colleagues nationwide. By all measures (unemployment, state budget shortfall, foreclosures, etc.) Nevada has been one of the hardest hit states in the current recession. While knowledge gained from this survey was useful (and current), what effect it will have in changing the cost structure is, now, on hold. In the spirit of support among the libraries in the same system of higher education, and in continuing to demonstrate serious shared efficiencies (by maintaining one joint system as opposed to five individual systems), no new fee structure will be implemented in the short term. At the appropriate time, different costing structures such as those elicited in the survey results will merit closer attention.

\section{References}

1. Jason Vaughan, "A Library's Integrated Online Library System: Assessment and New Hardware Implementation," Information Technology and Libraries 23, no. 2 (June 2004): 50-57.

2. Innovative Interfaces, "About Us: History," http://www .iii.com/about/history.shtml (accessed May 17, 2010). 